\title{
A Survey Study to Gather Requirements for Designing a Mobile Service to Enhance Learning from Cultural Heritage
}

\author{
Alaa Alkhafaji ${ }^{1}$, Sanaz Fallahkhair ${ }^{2}$, Mihaela Cocea ${ }^{1,}$ and Jonathan Crellin ${ }^{1}$ \\ ${ }^{1}$ School of Computing, University of Portsmouth, Buckingham Building, Portsmouth, UK \\ \{alaa.alkhafaji, mihaela.cocea, jonathan.crellin\} @port.ac.uk \\ ${ }^{2}$ School of Computing, University of Brighton, Cockcroft Building, Brighton, UK \\ S.Fallahkhair@brighton.ac.uk
}

\begin{abstract}
This study was carried out to gather user requirements using a questionnaire survey. The study has investigated how people may use mobile location-aware technologies for learning purposes in cultural heritage contexts. This paper presents the results of this survey study and outlines a number of challenges for further development.
\end{abstract}

Keyword: Mobile learning; Informal learning; Location-based; Cultural heritage

\section{Introduction}

Learning occurs while people are experiencing and being engaged in different types of activities [1] . Learning from experiences is a notion that was originally developed by the theorist John Dewey in his book "Experience and Education" (Dewey, 1938). Dewey's theory has served as a foundation stone for informal learning that was developed by Malcolm Knowles in 1950, in his publication "Informal Adult Education" [2].

Engaging in aspects of cultural heritage forms an important facet of the informal learning process. Since cultural heritage reflects the identity of most societies [3], it is important for people to learn more about the historical significance of heritage sites. This may help people appreciate their history, which could further promote a sense of loyalty and engagement [4]. Technologies, such as mobile learning, have already been used to support learning from cultural heritage sites, which help learning independent of time and place [5].

This study was conducted in the form of a survey, with data being gathered using a questionnaire technique to elicit user requirements for developing a mobile location-based learning service to be used at cultural heritage sites. The results of this study act as a cornerstone in designing the first version of the user requirements for 
developing a mobile location-based service to support informal learning at cultural heritage sites.

\section{The Survey Study}

The survey study was conducted to elicit user requirements for developing a mobile location-based learning service with respect to cultural heritage sites.

A questionnaire technique was used to gather user requirements within the usercentered design approach. The questionnaire was designed based on the themes that emerged from a previous focus group study [6]. The "Convenience Method" of sampling was used to recruit participants [7]. The study was carried out between $17^{\text {th }} \mathrm{Feb}$ and $17^{\text {th }}$ March 2015. The data was analyzed using the SPSS software [8]. A simple statistical analysis was used to obtain frequencies of the nominal data.

189 participants responded to this survey. The participants' age ranged from 18 to $70+$ years old. $47 \%$ of participants were male and $52 \%$ were female. $47 \%$ of participants were students, $33 \%$ were employed and $12 \%$ were retired. The remainders were: unemployed $(4 \%)$ or self-employed $(3 \%)$. $3 \%$ of participants stated different occupations such as researcher, independent, and semi-retired.

\section{The Results}

This study has investigated how people my use mobile technology for learning purposes in cultural heritage contexts. The section presents the summary of the results.

The results show some features and services that people would like to use through their mobile device which include information in multiple modes: images (74\%), texts (70\%), audio (49\%) and video (47\%). Participants claimed that they would like to use different services at cultural heritage sites. The most popular services include :1) to get directions $(75 \%), 2)$ to find the nearby cultural heritage places $(65 \%), 3)$ to find the nearest services $(56 \%), 4)$ both services, to get historical information while people walk around, and finding out extra information about the sites (53\%), 5) to preorganized a visit $(50 \%)$. Furthermore, $62 \%$ of participants said they would like to customize their mobile app based on their interest.

Participants were asked to choose the service that they think of as a type of learning, in order to understand how they construe learning. The results revealed that $85 \%$ of respondents consider online courses as learning, $78 \%$ of respondents said accessing online services is a type of learning, $76 \%$ of respondents think that accessing specific information is a type of learning and $67 \%$ of respondents consider using a dictionary is a type of learning. Interestingly, only $36 \%$ and $31 \%$ of respondents believe that accessing general information and getting directions respectively are types of learning.

Some challenges were highlighted by the results regarding using mobile devices at cultural heritage sites. Some participants said that they do not use mobile devices at cultural heritage sites (23\%); respondents stated several reasons for that: 1) $57 \%$ of 
them claimed that the mobile device distract them during the tour, 2) $20 \%$ of them do not use mobile devices due to a poor network quality, 3) $13 \%$ of them reported that it is not easy to follow the instructions, 4) $11 \%$ of respondents said that the available applications do not meet their needs. In addition, $15 \%$ of respondents reported different reasons such as: weather limitation "would need a waterproof tablet.

\section{Discussion}

The questionnaire technique used in this study allowed the gathering of a wide range of data. This in turn gives a clear understanding of how people differ in the way they use mobile devices at cultural heritage sites. The findings have significant implications for the development mobile learning services to be used in cultural heritage contexts.

The results indicate factors that will be useful in designing mobile-location based leaning services. These can be summarized as: considering user profile and adapt services based on users' interests, presenting information in multiple modalities, and providing instant information based on the user location which supports situated learning.

An interesting issue that was revealed is the different perceptions of learning. People have different understanding about the meaning of 'learning' [9]. Based on the results, learning could be classified into several categories: 1) acquiring formal information such as accessing online courses, which could help to enhance an individual's professional life; 2) acquiring information that could enhance an individual's skills; 3 ) acquiring informal information that could be helpful to enhance an individual's personal knowledge; 4) acquiring general information that could assist in individual's daily life. Learning from experiences could include all aforementioned learning categories. Since learning interweaves with people's daily life, it could be hard for it to be distinguished as learning [10]. We can infer that learning could be happening incidentally with the learning showing little awareness that learning is taking place.

Finally, the current study has underlined some challenges regarding using mobile devices for learning purposes at cultural heritage sites. The challenges include physical aspects of the devices, such as the screen size and the network. The increasing capabilities of tablets and smartphones may reduce the importance of these factors. Furthermore, a minority find mobile devices distract from the enjoyment the visit. A possible explanation for this issue the interruption caused by the switching visual attention between the device and the exhibit. Using Smart Glasses could help with this by overlaying data on a user's visual field. In addition, an interesting issue has emerged through the study such as the weather, as some people reported that the need for a waterproof device given how frequently it rains in the UK. Possibly smart glasses might help with this too. Finally, an issue regarding the quality of network, not considered in this research, but could be an important issue for further research. 


\section{$5 \quad$ Conclusion and Further Work}

A summary of a survey study has been presented in this paper, which was carried out as a part of a series of studies designed to gather user requirements. A questionnaire technique was used in this study. This study forms a stage of a research project, which is intending to develop a mobile location-based learning service with respect to cultural heritage contexts. There are a number of areas that we envision to carry out further work: First, to conduct further steps to fully eliciting of users requirements, by conducting interviews with end-users and museum staff, to gain in-depth details regarding using mobile devices for learning purposes. Second, to design a task model based on the results of the combination of this study and the interview study. Third, to develop a prototype mobile as a proof of concept based on the task model. Next, usability evaluation will be conducted. Finally, a list of guidelines will be for future mobile application development in this domain.

\section{References}

1. Schunk, D.H.: Learning theories. Printice Hall Inc., New Jersey (1996)

2. Smith, M.K., Malcolm Knowles, informal adult education, self-direction and andragogy (2002)

3. Vidal González, M.: Intangible heritage tourism and identity. Tourism management: p. 807-810 (2008).

4. UNESCO: Managing Cultural Wold Heritage: The United Nations Educational, Scientific and Cultural Organization (UNESCO), Paris: France (2013).

5. Sharples, M.: The Design of Personal Mobile Technologies for Lifelong Learning. Computer \& Education: p. 177-193 (2000)

6. Alkhafaji, A., S. Fallahkhair, and M. Cocea: Towards gathering initial requirements of developing a mobile service to support informal learning at cultural heritage sites. Cognition And Exploratory Learning In The Digital Age (CELDA 2015): p. 51 (2015).

7. Barnett, V.: Sample survey principles and methods: Edward Arnold London.

8. Greasley, P., Quantitative data analysis using SPSS: An introduction for health \& social science. 2007: McGraw-Hill Education, UK (1991)

9. Schmeck, R.R.: Learning strategies and learning styles: Springer Science \& Business Media (1988)

10. Vavoula, G.: KLeOS: A Knowledge and Learning Organisation System in Support of lifelong Learning, $\mathrm{PhD}$ thessis, University of Birmingham, Uk (2003) 